\title{
A IGREJA, O ESTADO E A BOLA: HISTÓRIA DO ESPORTE ENTRE OS ÍNDIOS DO BRASIL CENTRAL ${ }^{1}$
}

\author{
Cleber Dias \\ Universidade Federal de Goiás, Goiânia, Goiás, Brasil
}

\begin{abstract}
Resumo
O objetivo deste trabalho é analisar a história da difusão de esportes entre os índios do Brasil Central, apresentando alguns dados preliminares a esse respeito, além de sumariar uma agenda de pesquisas e um quadro teórico possível para a interpretação dessa relação. Ações do Estado e de missionários religiosos foram as duas principais medidas responsáveis pela disseminação de esportes entre os índios dessa região. Diferente do que algumas interpretações correntes afirmam, o significado histórico desse processo não necessariamente representou a destruição das culturas indígenas tradicionais, embora tenham sido estas, geralmente, a intenção dos agentes responsáveis pelo processo.
\end{abstract}

Palavras-chave: História. Esporte. Índios.

Caro irmão Roberto Dinamite - VASCO

Eu estou escrevendo para o senhor como que vai o jogo. Eu conheço do Vasco, eu torcedor do Vasco. Porque o senhor não marcou com o Flamengo? Quase ganharam. Eu vou rezar para todo o time do Vasco. Eu abraço para todos. Roberto porque você não fica Zanata? Torcedor do Flamengo reclamando do Vasco, ninguém não gosta, só ele gosta Fluminense, torcedor Rivelino tem muita gente. Nós somos poucos. Meu nome Carlos outro Tomás. Quando vai jogar com o Fluminense poder vencerem. Eu mandei carta para jogador do time da turma do Vasco, Mazzaropi, Orlando, Zanata, Ramo, Abel, Roberto, Paulo Ro-

1-Esse estudo contou com apoio do Conselho Nacional de Desenvolvimento Científico e Tecnológico (CNPq) e do Centro de Desenvolvimento do Esporte Recreativo e do Lazer (Rede Cedes), do Ministério do Esporte. A maior parte da pesquisa realizou-se nos acervos do Instituto Histórico Estadual de Goiás, em Goiânia; no Arquivo Público do estado de Mato Grosso, em Cuiabá; e no Museu do Índio, no Rio de Janeiro, a cujos funcionários devo os mais sinceros agradecimentos. Também agradeço aos colegas da Licenciatura Intercultural Indígena, da Universidade Federal de Goiás, por criarem uma ambiência intelectual extremamente estimulante. Aos alunos Karajá, Krikati, Tapirapé, Canela, Guajajara e Xerente, da turma de 2011 desse curso, pela honrosa oportunidade de discutir parte das ideias desse artigo no verão de 2012.

Pensar a Prática, Goiânia, v. 15, n. 1, p. 1-271, jan./mar. 2012 
berto, Paulinho, Zé Amaro, Gaucho, Marco Antonio, Fumalho etc. eu conheço estes jogadores. Uma vez eu escrevi para o senhor, o senhor não me conhece, eu estou olhando com a revista, com o rádio. Roberto conversa para mim com carta, pode escrever para mim, não sei endereço por isto escreve para mim certo? Pode contar para todos os seus companheiros, também para o seu pai, também para a sua mãe, também para os seus parentes. Eu sou Xavante, eu estou estudando no colégio, estou estudando a terceira série, eu contei para o senhor para saber, alguns não conhecem este São Marcos, o senhor pode acreditar, o senhor não fala mal, pode falar assim este selvagem, não pensa assim, nós agora estamos estudando com português, também com matemática, já conhecemos. O senhor vai escrever para mim com carta também para escrever para mim. Ramon com que vai estar no jogo mais tarde eu vou lá para estudar, agora eu sou ainda adolescente, eu wapté, quando eu fico moço não tem minha noiva, ainda não casei, agora eu sou 14 anos de 1977. Quando eu fico moço eu vou visitar no Rio de Janeiro. Eu com saudade lhe envio estas poucas linhas no Rio de Janeiro. Roberto quero dizer que ainda estou com laço da amizade, este é mais um motivo para não esquecer desta carta, cabou, taimbo. Um abraço para todos daí principalmente para você. Vasco. Roberto amigo - Tsawidi.

Carta de um índio Xavante, da aldeia de São Marcos, Mato Grosso, a Roberto Dinamite, jogador de futebol do Vasco da Gama, do Rio de Janeiro, no final dos anos 1970 (apud., VIANNA, 2008, p. 56-57).

\section{Introdução}

tualmente, o esporte, e particularmente o futebol, é um marcante
elemento da cultura de muitas comunidades indígenas. Em al-
guns casos, o jogo é praticado ou consumido cotidianamente, por ho-
mens e mulheres, adultos e crianças, com muito entusiasmo. Vários
pesquisadores têm registrado o destaque atribuído a essas práticas na
rotina de algumas comunidades, onde a própria centralidade dos cam-
pos de esporte na organização espacial das aldeias pode ser apontada
como resultado da importância dessa prática. De acordo com José Fas-
sheber (2010, p. 108), comentando a questão entre os Kaigang, "esta
disposição privilegiada [do campo de futebol] permite a reunião de um 
número expressivo de moradores não só das vizinhanças como de famílias mais isoladas". Segundo ele, "é comum ver nas encostas em volta do campo principal, a presença de famílias inteiras admirando desde partidas improvisadas por meninos e adultos até torneios e 'jogos amistosos' com outras TIs [Terras Indígenas] ou contra os Fóg [não-índio]". No mesmo sentido, Ángel Delgado e Guillermo Gómez (2010) anotaram que entre os Yanomami da Venezuela, campos esportivos ocupam às vezes até $30 \%$ do território das aldeias.

Mas quando, como e por que razão o esporte começou a ser praticado por índios? Ao menos desde o final dos anos 1950, quando se intensificava no Brasil o trabalho antropológico entre algumas etnias, tem-se registro não só da presença do futebol, como também de um considerável entusiasmo de alguns povos diante dessas práticas. Entre 1958 e 1964, enquanto realizava trabalho de campo junto aos Xavantes, o antropólogo Maybury-Lewis (1984, p. 61) já comentava sobre "a paixão, ou pode-se mesmo dizer, o vício do futebol". De acordo com ele, já naquela época, "todos jogavam, jovens e velhos, e a toda hora".

Mais que saber o momento e as maneiras através das quais os indígenas do Brasil Central entraram em contato com a prática esportiva, interessa também investigar o significado desse processo para a dinâmica cultural desses grupos. Nesse sentido, sem a pretensão de responder em definitivo essas questões, o objetivo desse trabalho é apresentar dados preliminares de uma pesquisa sobre a história do esporte entre os índios da região, além de sumariar uma agenda de pesquisas e um quadro teórico possível para a interpretação dessa relação histórica, entre esportes e culturas indígenas. Meu argumento é o de que a disseminação de esportes entre indígenas do Brasil Central se deu, basicamente, através da intermediação de dois complexos institucionais: a Igreja e o Estado. A primeira o faria fundamentalmente através de missões religiosas, católicas e protestantes. Já o segundo o faria através da construção de linhas telegráficas ou através da administração de Postos do Serviço de Proteção aos Índios. De diferentes formas, ambas as iniciativas estariam ligadas à tentativa de propagação de um novo paradigma civilizacional, que, em certa medida, também disse respeito à difusão de esportes.

Todavia, o sucesso desse empreendimento civilizatório, quando avaliado em razão das expectativas mesmo desses agentes do progres$s o$, é apenas relativo, pois povos indígenas não necessariamente se 
comportaram tal como desejado por eles (DIACON, 2006; GARFIELD, 2011). Em verdade, por meio de sutis e criativos mecanismos de negociação, esses grupos, em muitos casos, têm agenciado os termos da sua própria incorporação à "sociedade civilizada". Nesse sentido, para além de ter sido uma ferramenta disciplinadora de corpos, ao mesmo tempo em que nunca deixou de sê-lo, os esportes constituíramse também como um recurso potencial para mobilização e articulação de práticas e discursos ligados às pautas de reivindicação dos próprios povos indígenas, oferecendo-lhes oportunidades de sociabilização, de ação política e até mesmo de reforço às tradições e identidades étnicas indígenas (FIALHO, SILVA, 2010; FASSHEBER, 2010; VIANNA, 2008; NASCIMENTO JÚNIOR, FAUSTINO, 2010; TASSINARI, 2003).

\section{Esporte e ação missionária no Brasil Central}

Missões religiosas estão entre as primeiras ações a estabelecer contato regular e sistemático entre povos indígenas do Brasil. Nesse contexto, a presença de missionários cristãos (católicos ou protestantes), não raro comprometidos com a moralização dos costumes através da educação do corpo, parece ter servido como uma das condições de possibilidade para o início do esporte nessas regiões.

Religiosos cristãos desenvolveram vínculos com a prática esportiva desde os meados do século XIX (TEIXEIRA DA SILVA, 2006). Entre católicos brasileiros, desde 1871, têm-se notícias de excursões pela Europa de padres jesuítas do colégio de Itu, em São Paulo, onde conheciam escolas em que a prática do esporte era já um instrumento pedagógico bastante disseminado, como era o caso do Colégio de Vannes, na França, ou da Harrow School, na Inglaterra; ambos visitados pelos jesuítas brasileiros nesse período. A partir de 1880, quando o padre José Mantero, que conhecera essas escolas, assumiu a Reitoria do Colégio de Itu, práticas esportivas foram definitivamente estabelecidas como instrumentos da promoção da moral e da virilidade. Segundo um manual da corporação datado, justamente, de 1880, "onde não folga o corpo e não se distrai o espírito reinam o aborrecimento, o enfado, o desânimo, a preguiça e outras condições favoráveis ao relaxamento e prejudiciais à moralidade; os exercícios corporais de movimento se impõem como condição física e moral" (apud., NETO, 2002, p. 19). 
Entre os protestantes, a doutrina da Cristandade Muscular é um dos exemplos mais acabados do envolvimento desses religiosos com a prática e a valorização de esportes e outras atividades físicas. Desenvolvida inicialmente na Inglaterra, com articulações com lideranças do Socialismo Cristão Inglês, dentre as quais, o reverendo Thomas Arnold, diretor do Rugby College e árduo defensor da inclusão do esporte nos currículos escolares ingleses (MANGAN, 1981), a doutrina da Cristandade Muscular propugnava que o fortalecimento do corpo moralizava os costumes e fortalecia o caráter. Segundo essas ideias, a moralidade cristã precisava pressupor a promoção de um desenvolvimento harmonioso entre corpo, mente e espírito. No final da década de 1850, os princípios da Cristandade Muscular já eram parte integrante do sistema educacional público inglês (WATSON, WEIR, FRIEND, 2005). Pouco antes, em 1844, motivado pelas insalubres condições de vida da Inglaterra oitocentista e animado pelos princípios gerais da Cristandade Muscular, criou-se uma entidade para caridade, promoção de hábitos saudáveis e difusão dos valores cristãos, a Associação Cristã de Moços (ACM), cujo papel seria mais tarde decisivo na disseminação de práticas esportivas (BINFIELD, 1973). A partir de 1850, sedes da ACM eram fundadas na Holanda, Índia, Austrália, Alemanha e Canadá. Em 1860, segundo cálculos de Clifford Putney (2001), a entidade já possuía mais de 250 sedes. No Brasil, a primeira foi criada em 1893, na sede da sociedade Bíblica do Rio de Janeiro, com o objetivo de disseminar preceitos religiosos da fé cristã, promover a saúde e combater práticas de lazer "ilícitas", entre as quais, os jogos de azar, o homossexualismo e o consumo de bebidas (CANCELLA, 2010).

O trabalho de pregação protestante iniciou-se mais sistematicamente no Brasil na década de 1860 , através da criação de um jornal evangélico, um presbitério e um seminário. Em 1870, missionários da Igreja Presbiteriana do norte dos Estados Unidos, criavam, em São Paulo, a Escola Americana, mais tarde Mackenzie College, cujos alunos e ex-alunos formariam, em 1898, a Associação Atlética Mackenzie College, uma das primeiras agremiações de São Paulo a desenvolver o futebol. Outros missionários norte-americanos da Igreja Presbiteriana concentravam-se na região do Triângulo Mineiro, no sul de Goiás e em algumas cidades do nordeste, especialmente Recife e Sergipe. Na transição dos séculos XIX e XX, a intensificação da ação protestante nessas regiões por meio da educação, da religião e da saú- 
de, iniciou nova fase evangelizadora, tornando-se, nas palavras de Ester Nascimento (2007, p. 23), "pólo irradiador de um modelo cultural norte-americano que se expandiria para Sergipe, Mato Grosso, Goiás e Norte de Minas Gerais". Nessas ações destacava-se sempre a importância atribuída à educação do corpo, especialmente através dos esportes e dos exercícios físicos. Tanto que a simbologia que representava caracteristicamente a presença desses religiosos nessas regiões manifestava-se através de uma simbologia que incluía, além da igreja e da escola, quadras de esportes (NASCIMENTO, 2007).

Alguns desses religiosos que desbravavam o hinterland brasileiro compunham uma rede de relações bastante estreita com outros atores do cenário protestante no Brasil, incluindo aqueles envolvidos com a promoção de esportes e outras atividades físicas nos principais centros urbanos do país. Quando uma missão religiosa partiu para dar início ao trabalho de evangelização de índios no "sertão do Mato Grosso", em 1929, Eurípedes C. Menezes, presidente da ACM de São Paulo à época, brindou a iniciativa nas páginas do jornal $O$ Puritano como um "auspicioso acontecimento", declarando orgulhosamente que era amigo de todas as pessoas envolvidas na iniciativa (apud. GONÇALVES, 2009, p. 159).

A partir dessa época, toda a região do Brasil Central foi intensivamente assediada por missões religiosas, sobretudo protestantes, muitas delas lideradas por estrangeiros. Robin Wright (1992, p. 264), referindo-se a este processo no noroeste amazônico, chegou a falar de uma "era das missões". No Brasil Central, especificamente, tem-se notícias, desde a década de 1920, de iniciativas como a do norte-americano Alvin Nathan Allen, membro da Igreja Adventista do Sétimo Dia, que fundou e dirigiu a "Missão Carajá". Na mesma época, outro norteamericano, Willian Azel Cook, do quadro do Presbyterian Board of Foreign Missions, realizava missão evangelizadora na região, no mesmo momento em que ainda se tem notícia das ações da British Mission to Mato Grosso.

Nesse contexto, povos indígenas do Brasil Central podiam estabelecer contato em diferentes graus com hábitos e costumes até então desconhecidos para a maioria deles. De acordo com Hermano Ribeiro da Silva $(1959$, p. 68), que a exemplo de outros viajantes do período, cruzou com esses missionários durante viagem em 1932, muitas vezes eles carregavam consigo vários artefatos, como ricas coleções de discos, com o que "enchiam o Araguaia de trechos sinfônicos e árias de 
óperas". Nesse contexto, o esporte também podia ser uma das inovações apresentadas pelos religiosos. Por volta de 1920, a aproximadamente 60 quilômetros da foz do rio Tapirapé, afluente do rio Araguaia, o inglês Archie MacIntyre, da Evangelical Union South América, dirigia uma missão entre os índios Karajá. Ao que parece, MacIntyre, no Brasil desde 1907, era grande apreciador da prática esportiva. No período em que o inglês viveu na cidade de Goiás, ponto de passagem obrigatório para viajantes interessados em descer o Araguaia, MacIntyre teria se envolvido e incentivado a organização das primeiras partidas de futebol na cidade. Segundo memórias de Ofélia Socrates do Nascimento Monteiro (1974, p. 81), em informação reiterada por Albatenio de Godoi (1969), "em 1908 o ministro protestante Archie Macintire [sic], amante de esportes, tomou direção dos jogos, disciplinou-os, incentivou-os".

De maneira mais óbvia e sistemática, missionários salesianos aparecem como um dos principais responsáveis pela disseminação do esporte entre índios da região, sobretudo os Bororo, entre os quais atuaram através de aldeamentos desde os fins do século XIX ${ }^{2}$. Padre Osvaldo Scotti, em entrevista ao antropólogo Brito Vianna (2008, p. 244), falou sobre o campo de esporte como ponto de partida obrigatório da pedagogia salesiana. Segundo este relato, "sempre que se faz uma obra salesiana, a primeira coisa é fazer o campo de futebol. Depois, faz-se a capela e a sala de aula. Pode faltar a capela e pode faltar a sala de aula, mas nunca falta o campo de esporte".

O sistema educativo praticado pelos salesianos, de fato, dava grande importância às manifestações lúdicas e recreativas. $\mathrm{O}$ modelo era fornecido pelos Oratórios Festivos, criados na Itália por Dom Bosco, líder e fundador da Sociedade Salesiana, com o objetivo de cuidar de meninos órfãos de Turim. Seus princípios gerais, chamados "pedagogia ou sistema preventivo", delineados em meados de 1850, basea-

2-A atuação dos salesianos no Brasil Central iniciou-se em 1894, no Mato Grosso, onde o bispo de Cuiabá, Dom Carlos D'Amour, solicitara oito mil contos de réis ao presidente desse estado para custear a viagem dos religiosos, além de ter ido pessoalmente até Roma solicitar colaboração da Irmandade. Em 1901, a partir de Mato Grosso, os salesianos inauguraram a Missão dos Tachos, às margens do afluente dos rios Garça e Araguaia. Em 1902, na Reserva do Meruri, estabeleceram a Missão Sagrado Coração de Jesus. Em 1906, às margens do Rio Sangradouro, estabeleceram a Missão de São José; todas com marcante presença Bororo.

Pensar a Prática, Goiânia, v. 15, n. 1, p. 1-271, jan./mar. 2012 154 
vam-se na "suavidade", "afeição", "exclusão de todo castigo violento" e "atração através de jogos e divertimentos". Segundo os ensinamos do próprio Dom Bosco, seus métodos eram "simplíssimos". Bastava dar aos jovens plena liberdade de fazer as coisas que mais lhes agradassem: correr, saltar, gritar e divertir-se a seu gosto. Nesse sentido, a ginástica, a música, a declamação, os passeios e os campos de jogos em geral eram vistos como meios eficazes para manter a disciplina, coadunar a moralidade e promover a saúde dos alunos (BORGES, 2005).

No Brasil, segundo Adilson Francisco (2010, p. 150-151), que estudou a história do envolvimento dos salesianos com a educação no Mato Grosso, "nestes encontros semanais [os Oratórios Festivos], os jogos recreativos, sobretudo o futebol e as premiações, eram o chamariz e estímulo para uma clientela urbana".

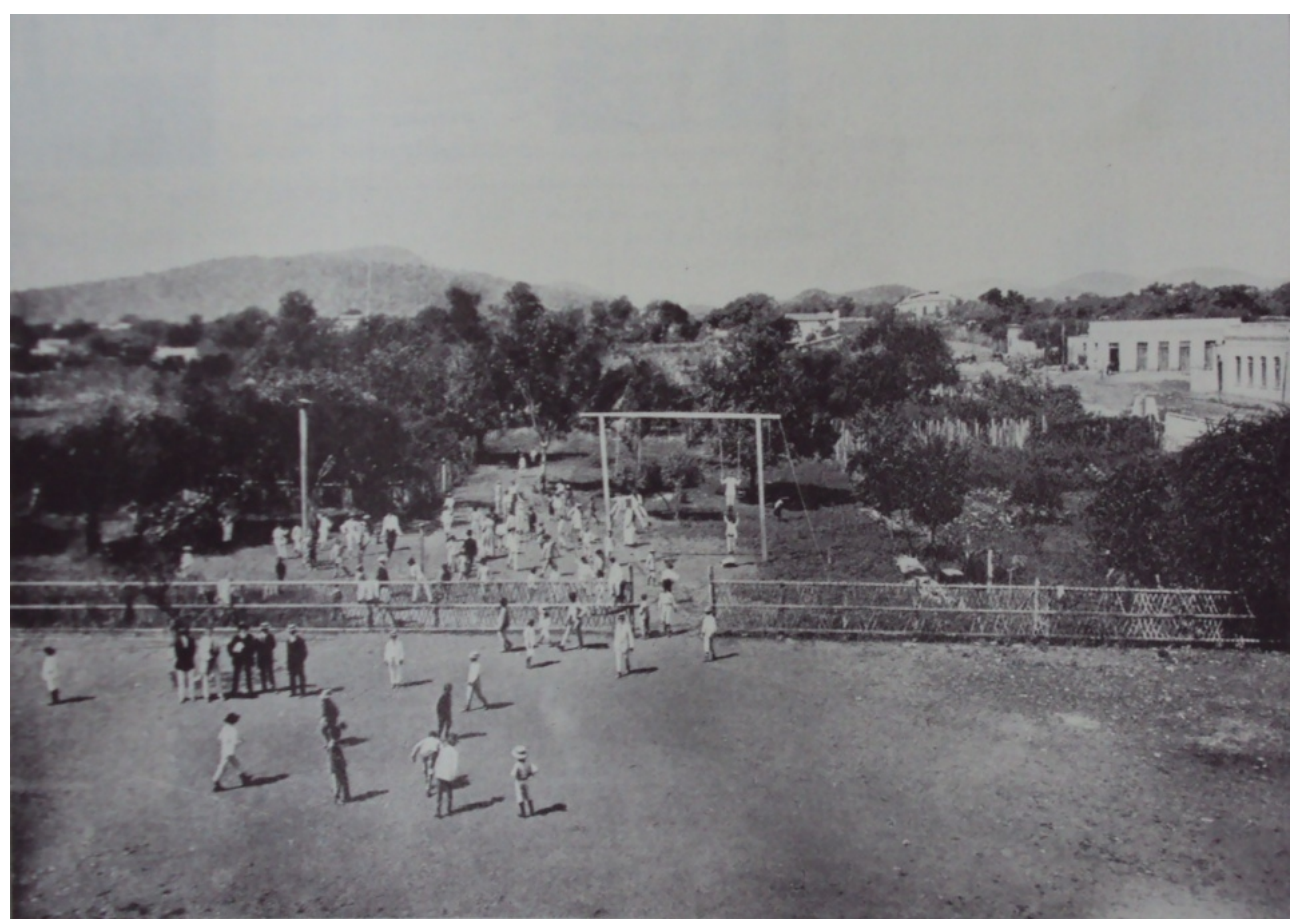

Imagem 1: Jardim de Gymnastica do Collegio Santa Thereza, dos salesianos, em Corumbá, Mato Grosso. Fonte: Ayala (1914, p. 197).

Para além dos círculos urbanos, o ensino da ginástica e do esporte figurou também nas ações dos salesianos junto aos índios da região. De acordo com Maria Augusta de Castilho (2000), em toda parte do Brasil Central, o ensino promovido pelos salesianos incluía o programa governamental padrão para escolas primárias: língua portuguesa, 
matemática, mais oficinas de carpintaria, sapataria, curtume e alvenaria, além de aulas de canto, música e ginástica. Claudia Menezes (1999, p. 329), por seu turno, fala mesmo de uma "ênfase dada aos exercícios que desenvolvem o físico dando-lhe vigor e recreação". Segundo ela, a pedagogia salesiana deve ser compreendida à luz das representações cristãs modernas, "que encaram o controle sobre o corpo como meio e instrumento da prática salvacionista". De fato, conforme apontaram Bale e Cronin (2003), em situações de dominação colonial, o corpo é um dos principais símbolos a definir e caracterizar a condição do primitivo.

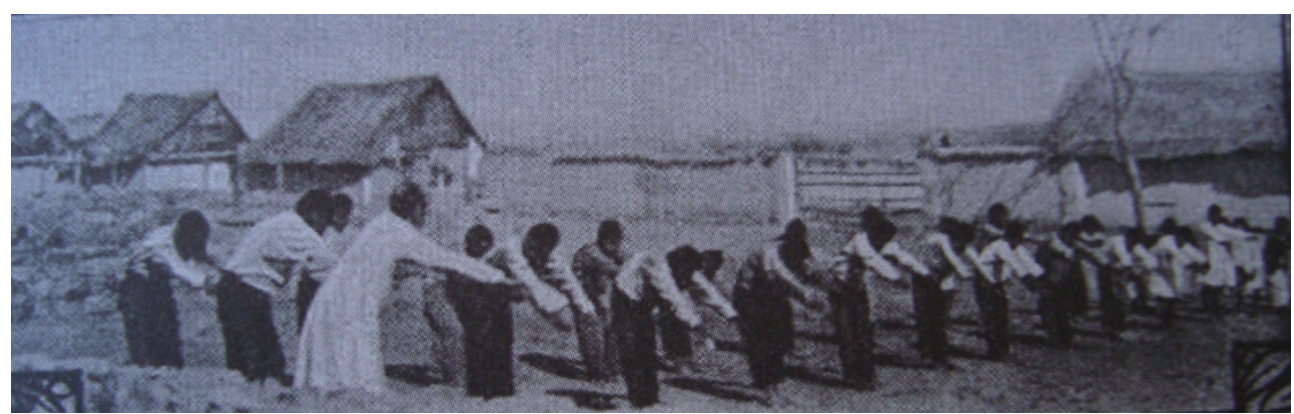

Imagem 2: Aula de ginástica ministrada por padre salesiano, na Colônia Sagrado Coração de Jesus, no vale do Meruri, Mato Grosso. Fonte: Boletim Salesiano, 1907, apud. Francisco (2010, p. 131).

A educação do corpo, portanto, tinha relativa centralidade na ação missionária salesiana junto aos índios, embora documentos escritos às vezes não a revelem tão explicitamente. Imagens, porém, produzidas claramente com intenções propagandísticas, como as vinculadas sobre a obra salesiana entre os "selvagens do Brasil" no Boletim Salesiano (Imagem 2), registram situações em que padres aparecem coordenando exercícios como parte das suas atividades educativas entre índios do Brasil Central.

\section{Esporte na Comissão Rondon}

Outro forte vetor de intermediação entre indígenas e o "mundo dos brancos" foi o Estado, sobretudo durante a República Velha, quando a política indigenista sofreu mudanças de direção. Segundo Gagliardi (1989), nos primeiros vinte anos do regime republicano, o relacionamento do Estado com os indígenas não sofreu nenhuma alteração significativa. $\mathrm{O}$ ordenamento jurídico do Império no que concerne aos povos indígenas foi mantido praticamente inalterado até por volta do 
fim da primeira década do século XX. Daí em diante, uma crescente mobilização política ao redor da questão indígena teve lugar, culminando na formalização de um órgão federal dedicado, especificamente, à proteção e assistência aos índios.

Antes, porém, uma das principais esferas institucionais que acabaria responsável pelo estabelecimento de contatos com "índios selvagens" do "sertão brasileiro" seria a Comissão Rondon, criada em 1907. A iniciativa fora apresentada como recurso estratégico para civilizar o sertão, garantir a posse das fronteiras, integrar regiões e vencer o atraso do interior através da promoção de sua ocupação produtiva (MACIEL, 2001). Em alguns casos, esse contexto geral foi determinante para a disseminação de práticas esportivas entre indígenas do Brasil Central.

Nessa época, a acolhida de ideais positivistas por parte da elite militar do Exército - instituição responsável pela construção de linhas telegráficas desde os anos 1880 - favorecia a crença de que a disseminação da tecnologia, nesse caso, o telégrafo, aceleraria a evolução civilizatória das partes mais "atrasadas" do país. Além das razões de ordem militar, política e econômica, as justificativas para expansão das linhas telegráficas demonstravam fortemente razões civilizatórias. Desde que esta tecnologia chegara ao Brasil, em 1808, sempre existiram vozes destacando-a como um benefício inequívoco da civilização moderna $^{3}$. Em várias ocasiões, o próprio Rondon enfatizou que o tra-

3-Em 1808 entrou em funcionamento o primeiro telegráfico do Brasil, sob jurisdição do Ministério da Guerra. Parte dos argumentos para justificar o empreendimento baseava-se na sua utilidade para fins políticos, mas também militares. Por volta de 1840, além da capital, as províncias da Bahia, Pernambuco, Ceará, Maranhão e Santa Catarina já dispunham do serviço. Em 1852 foi inaugurada a primeira linha de telégrafo elétrico. Durante a guerra do Paraguai (1865-1870) ficou patente a necessidade de comunicações mais rápidas entre partes mais distantes do território brasileiro. Em 1886, inaugurou-se o cabo telegráfico submarino que ligava o Brasil à Europa. A partir de 1873, as províncias da Bahia, Pernambuco e Pará teriam, pela primeira vez, ligação telegráfica direta com a capital. Até 1886 , mais de 10.000 quilômetros de linhas telegráficas seriam instalados, no que Maciel (2001, p. 132) chama de "momento áureo da expansão da rede telegráfica sob o Império". Em 1894, um regulamento para os telégrafos estabeleceu competência exclusiva do governo federal para construir e explorar linhas interestaduais, o que mostra a preocupação com o assunto (MACIEL, 2001).

Pensar a Prática, Goiânia, v. 15, n. 1, p. 1-271, jan./mar. 2012 
balho de instalação de linhas telegráficas no sertão e sua incorporação ao mundo civilizado eram elementos de um só projeto. Segundo ele, "onde quer que chegue o telégrafo, por mais recôndito que seja o lugar, ali far-se-ão sentir os benéficos influxos da civilização" (Rondon, 1949, p. 9). Assim, aos olhos de seus realizadores, a instalação de linhas telegráficas não era apenas o estabelecimento de canais de comunicação entre diferentes partes do país, senão uma verdadeira epopeia em prol da civilização: verdadeira "sonda de progresso", como gostava de dizer Rondon. Foi dentro desse espírito e no momento em que se ampliava a prática do esporte e das atividades físicas no cotidiano das Forças Armadas (CANCELLA, 2011), que atividades como a ginástica, o futebol e outros esportes foram aprendidas e utilizadas.

Após o estabelecimento das estações telegráficas, a Comissão Rondon estimulava a criação de núcleos populacionais no seu entorno, com o objetivo de incentivar o trabalho agrícola, educar a população das imediações, pacificar os índios e atrair novos imigrantes, tentando povoar a região. Particularmente, para o "progresso moral e mental", conforme diziam os relatórios da Comissão, criavam-se escolas dedicadas ao ensino da matemática, da língua portuguesa, dos ofícios agrícolas e mecânicos (notadamente a telegrafia), da música, da ginástica sueca e pouco mais tarde do futebol. Geralmente, os próprios funcionários da estação telegráfica, muitas vezes envolvidos com sua construção, eram os responsáveis pela educação dos meninos na escola. As meninas, sempre que possível, ficavam sob responsabilidade das esposas desses funcionários, motivo pelo qual se privilegiava a contratação de homens casados, quase sempre militares ou ex-militares do Exército.

Ao redor da Estação Telegráfica de Utiariti, ao noroeste de Cuiabá, se tem notícias de um funcionamento mais regular e sistemático da escola por volta do início da década de 1920, embora o início de suas atividades datasse de antes disso. Nessa época, com uma população aproximada de 120 índios Paresi, nove alunos indígenas e dois "civilizados" alternavam-se entre o estudo e o trabalho na lavoura como parte de suas atividades promovidas pela escola. Em 1925, um telegrama de Rondon endereçado a Xavier Junior, chefe do Escritório da Comissão, no Rio de Janeiro, mencionava os "excelentes serviços" prestados pelo cabo Vicente Sombra como "mestre de gynastica e exercícios militares aos índios parecis da Povoação Indígena Utiarity" (apud. BIGIO, 2003, p. 117). 
Tal como na história da relação dos religiosos com os índios da região, fontes escritas geralmente concentram-se mais na descrição dos "melhoramentos materiais" e "progressos nos trabalhos", quase não mencionando iniciativas ligadas à regulamentação dos passatempos e divertimentos indígenas. Fotografias, entretanto, como as de José Louro, um dos oficiais do Exército responsáveis pela produção do enorme acervo imagético da Comissão Rondon, registram alguns desses momentos iniciais da organização dos esportes entre indígenas, deixando entrever esse aspecto da vida social ${ }^{4}$. Numa delas, na mesma página que exibe a "vista do Núcleo fundado pela comissão em Utiariti para assistência aos índios Paresi" com sua "escola e banda de música", vêse também uma aula de ginástica sueca dirigida pelo inspetor Rubens Hignes, chefe do posto Utiarity, no que provavelmente seria auxiliado mais tarde pelo cabo Vicente Sombra (Imagem 3).

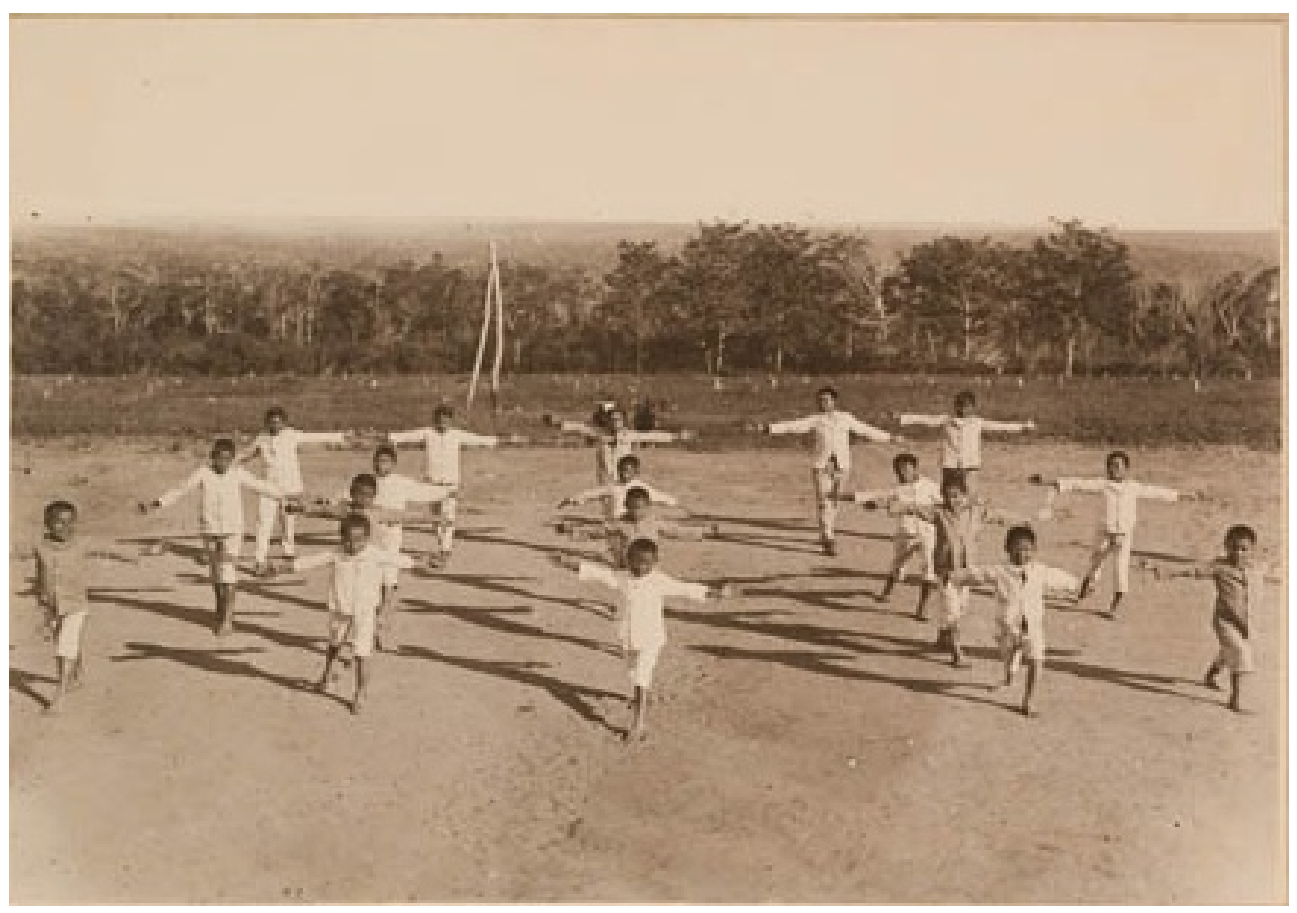

Imagem 3: Crianças Paresi praticando ginástica sueca no núcleo da Estação Telegráfica de Utiariti, Mato Grosso. Fonte: Comissão Rondon (1922, p. 289).

4-O amplo acervo de imagens produzido pelas décadas de trabalho de Rondon junto aos índios já recebeu atenção específica. São literalmente milhares de imagens produzidas, divulgadas e arquivadas, cujo resultado é a consagração de formas de se representar e compreender o índio no Brasil, conforme apontou Fernando Tacca (2001). É mesmo notável o reconhecimento precoce da importância de se registrar 


\section{Esporte e Serviço de Proteção aos Índios}

Além dos postos ao redor das estações telegráficas, instalações controladas pelo Serviço de Proteção aos Índios (SPI) foram outro importante elemento da difusão de esportes entre indígenas ligados às ações do poder estatal. Boa parte das circunstâncias no trabalho da Comissão Rondon marcou também a ação do SPI. Graças, inclusive, a sua relação desenvolvida com índios do Mato-Grosso, amplamente utilizados como mão de obra para a construção das linhas telegráficas (BIGIO, 2003), Rondon fora convidado a assumir também a direção do SPI no momento de sua criação, em $1910^{5}$.

Boa parte da atuação do SPI se deu através dos chamados "Postos Indígenas" (Rocha, 2003), que muitas vezes funcionaram também como canal para difusão de práticas esportivas, sobretudo depois de 1936, no contexto do governo de Getúlio Vargas, quando foi estabelecido novo regulamento para o Serviço, destacando-se a nacionalização e a incorporação dos silvícolas à "sociedade civilizada" como um dos seus principais objetivos. Nessa época, de acordo com Gagliardi (1989, p. 277, o grifo é meu.), "nos postos, o indígena deveria ser educado para o cumprimento dos deveres cívicos, através do conhecimento da higiene, da escola primária, de exercícios físicos, da instrução militar, da educação moral e cívica, do culto à bandeira". De maneira sintomática, $O$ índio e o esporte, uma espécie de filme publi-

em imagens a vida, os costumes e também as atividades desenvolvidas junto aos índios como estratégia intencional de sensibilização de autoridades e da opinião pública quanto à importância dos trabalhos junto aos índios. Depois de fracassarem as tentativas empreendidas pela Casa Muso, estabelecimento comercial de fotografia do Rio de Janeiro contratado com essa finalidade, em 1912, por sugestão do então tenente Luiz Thomas Reis, foi criada a "Secção de Cinematographia e Photographia" da Comissão Rondon, que contava com equipamentos bastante modernos e sofisticados para a época. Desde então, Rondon, em particular, preocupou-se sistematicamente não só em coordenar e ordenar a produção de filmes e fotografias, como também em arquivá-las e preservá-las (LASMAR, 2008).

5-O órgão, na verdade, fora criado como "Serviço de Proteção aos Índios e Localização de Trabalhadores Agrícolas". Apenas em 1918 seu nome fora alterado, abandonando a função de "localizar trabalhadores", passando, finalmente, a chamar-se tão somente "Serviço de Proteção aos Índios".

Pensar a Prática, Goiânia, v. 15, n. 1, p. 1-271, jan./mar. 2012 
citário produzido pelo SPI na década de 1940, tentando edificar a imagem de um índio já civilizado, "usando máquinas e apetrechos modernos", esforçava-se por mostrar a rotina do Posto Indígena Guarita, no Rio Grande do Sul, fortemente perpassada também pelo esporte, notadamente o voleibol e o futebol, "modernos", "salutares", "agradáveis" e "dinâmicos" desportos, enfatizava a voz do narrador em off na película. Por fim, concluía a mesma voz:

A vida e os costumes da gente do Posto Indígena Guarita oferecem perspectivas das mais interessantes sobre a capacidade de civilização e assimilação dos nossos silvícolas. Constituem também uma eloqüente demonstração dos benefícios que tem prestado o Serviço de Proteção aos Índios em sua missão pacificadora e civilizadora.

Mesmo antes disso, contudo, exercícios físicos, incluindo esportes, já faziam parte da rotina de alguns postos indígenas coordenados pelo SPI. Em 1929, o missionário Esthon Marques, da Missão Cauiá, no Mato Grosso, relatando nas páginas do jornal protestante $O$ estandarte sua viagem ao Posto Indígena Itaicuê (ou Itacu), dirigido à época pelo Sr. André Leite, deu notícias sobre um campo de esportes, localizado, segundo conta, bem ao centro do posto. Além de destacar que os indígenas residentes ali the pareceram "educados", Marques fez questão de destacar a iniciativa de construir um campo de futebol como "fruto do empenho e do esforço do encarregado do Posto que tentava tornar mais suave e deliciosa a vida dos silvícolas dando um aspecto de lugar civilizado ao local" (Apud. GONÇALVES, 2009, p. 189).

Nessa época, o SPI ingressava em novo contexto institucional. O fim da Primeira Grande Guerra liberou recursos e facilitou algumas das suas ações, sobretudo a criação de novos postos e inspetorias (LIMA, 1992). Entre 1925 e 1929, depois de ter superado período dificílimo, com propostas, inclusive, para seu fechamento, seu orçamento anual saltou da faixa dos 1.000 para mais de 3.500 cruzeiros (GAGLIARDI, 1989, p. 244). Foi o período em que a Inspetoria Regional 8, responsável por Goiás, mas anexada à de São Paulo em 1914, recebeu novo ânimo (BIGIO, 2003). Em novembro de 1924, Dr. Olegário Bastos, à época representante de Goiás no Congresso, pronunciou discurso reivindicando o restabelecimento de uma "inspectoria de índios" especificamente dedicada à Goiás, acusando o governo federal de de- 
dicar a Goiás apenas as sobras dos outros estados (O DEMOCRATA, 1924, p. 1).

Nesse contexto, em 1927, foi criado o Posto Redenção Indígena, na Ilha do Bananal, no rio Araguaia, chefiado por Manoel Silvino Bandeira de Mello, sertanista experiente que trabalhava no órgão praticamente desde sua fundação. Ali, Bandeira de Mello não mediu esforços para imprimir o que julgava serem "melhoramentos" para as cerca de 217 almas que viviam na região: 181 índios (Karajá, Xerente e Javaé), além de 36 "civilizados" (COSTA, 1930, p. 20). Um relatório de Bandeira de Mello datado de 1931, endereçado ao encarregado do SPI em Goiás à época, o Tenente Coronel Alencarliense Fernandes da Costa, antigo colaborador de Rondon, fala de alguns deles. Segundo o documento, em 1930, o posto tinha plantado, no total, mais de 34 hectares de arroz, milho, mandioca e cana-de-açúcar, além de vários pés de café, amendoim, banana, abacaxi, manga, laranja, jaca, limão, jambo e muitas outras frutas. Oficinas de beneficiamentos fabricavam açúcar, farinha, rapadura, fubá, arroz e sabão. Além disso, graças à presença do posto, destacava com entusiasmo o encarregado, instalaram-se escolas e distribuíram-se roupas. O posto, em suma, era tido e apresentado como instrumento de progresso e civilização.

Os esportes, embora não fossem explicitamente destacados nesses termos, figuravam como mais um recurso prático e símbolo para realização desses ideais. Darcy Bandeira de Mello, filho do encarregado do posto da ilha do Bananal, que já acompanhara seu pai anteriormente em trabalhos junto aos Kaigang e aos Bororo, auxiliava-lhe ali também. Valendo-se de suas experiências prévias com atividades esportivas na Associação Atlética de São Paulo, onde praticou natação, remo, corridas a pé, equitação e tiro ao alvo (MELLO, 1980 p. 124), o filho do encarregado do posto logo se pôs a animar a prática de esportes na ilha do Bananal. Segundo notícia publicada pelo jornal A platéa (1930, p. 4), "seus esforços foram plenamente coroados de êxito". Ainda segundo a reportagem, "dentro de um espaço de tempo muito reduzido, os jovens índios praticavam com enthusiasmo e maestria, várias modalidades de esportes, especialmente a natação, o pólo aquático e o futebol".

Ao lado de Darcy Bandeira de Mello, Lauro de Alencar Castello Branco, que a partir de 1929 começou a trabalhar como professor dos meninos no posto Redenção. De acordo com relatório do seu chefe imediato, "além de auxiliar todos os serviços deste Posto, dedica-se 
com muito interesse a organização dos esportes do mesmo" (MELLO, 1931, p. 6).

De fato, fotografias anexas ao relatório do encarregado do posto registram vários momentos de "instrucção physica dos alumnos da Escola Masculina", entre os quais, "exercícios", "desportos" e um "team de water-polo"6. O ano de 1931 iniciava-se já com a presença de artigos para futebol, além de bolas de water-polo e de "baske-boll" [sic] na lista de materiais do posto (MELLO, 1931, parte segunda, quadro n. 19). Nessa época, o posto chegara a conhecer o "Esporte Clube Índio Carajá", que em 1929 registrara 31 treinos e 7 jogos oficiais, além de 4 seções ordinárias e 3 extraordinárias (MELLO, 1931, parte segunda, quadro n. 23). Jogos oficiais eram partidas de futebol que já se apresentava como a modalidade mais popular também entre os índios da ilha do Bananal. A conservação do campo cabia a turma de índios solteiros, enquanto os casados se ocupavam em capinar as roças do posto e auxiliar "a turma dos civilizados nas derrubadas e nas plantações" (COSTA, 1930, p. 21). Partidas entre equipes só de índios contra equipes mistas de brancos e índios, realizadas todos os domingos, a partir das seis horas da tarde, "hora em que o sol é mais ou menos supportavel", dizia a reportagem do jornal A platéa (1930, p. 4), despertavam "verdadeira torcida de grandes assistências", sendo presenciada às vezes por toda a população da ilha, destacava de forma talvez exagerada a notícia do jornal.

6-No posto, segundo informava um relatório de Alencarliense da Costa (1930), encarregado do SPI em Goiás, foram fundadas três escolas em julho de 1929: a Escola José Bonifácio, que atendia meninos; a Escola Couto de Magalhães, dedicada às meninas e a Escola Gonçalves Dias, que atendia rapazes no período noturno. Em 1931, segundo relatório do encarregado do posto, a primeira registrava 29 alunos, 23 "Carajás" e 6 "civilizados"; a segunda contava 15 "Carajás" e 3 "civilizadas"; e a terceira, embora não tenha funcionado no quarto trimestre por falta de querosene, contava 9 "Carajás" e 13 "civilizados", sendo 2 "Caiapós", 2 "Cherentes" e 1 "Caraó" (Mello, 1931, parte segunda, quadro n. 9). Segundo Lima (1992), "a ênfase da ação protecionista a ser implementada pelo SPI residia na educação enquanto via de acesso à incorporação, isto abrangendo tanto atividades físicas quanto ensino agrícola e moral e cívica” (p. 165, o grifo é meu).

Pensar a Prática, Goiânia, v. 15, n. 1, p. 1-271, jan./mar. 2012 


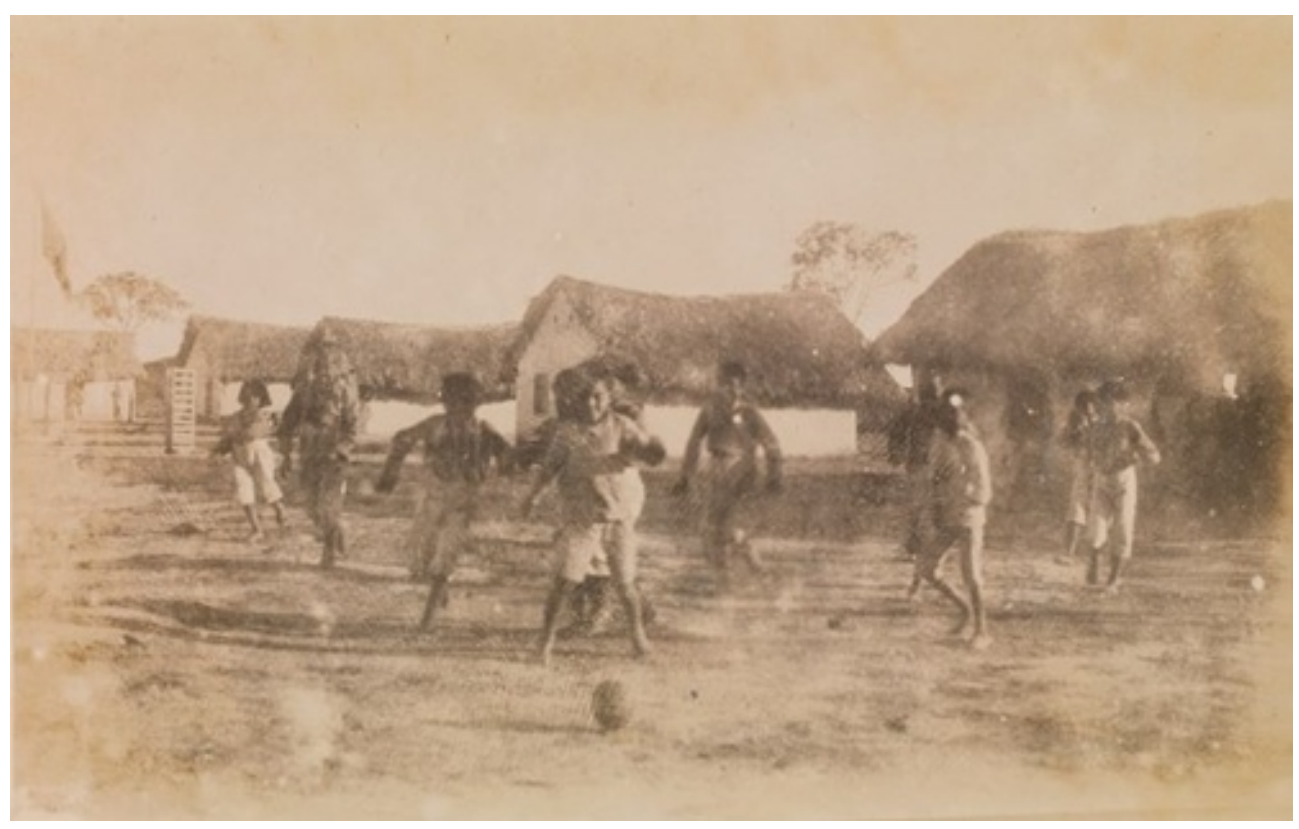

Imagem 4: Em 1929, alunos da escola José Bonifácio, na Ilha do Bananal, em Goiás, jogavam futebol como parte da sua "instrucção physica". Fonte: Costa (1930).

No fim, tais "curiosas iniciativas culturais", conforme as chamou Durval Rosa Sarmento Borges (1986, p. 360), eram mobilizadas como mais uma demonstração a reforçar os benefícios de se pacificar e aculturar índios do sertão. Conforme dissera o adventista Alvin Nathan Allen durante visita ao posto Redenção Indígena, em 1930, a escola, a lavoura e o campo de esportes, "fala[m] que os índios do Araguaia formarão uma parte importante entre os cidadãos do Brasil" (apud. FILHO, 2006, p. 267.). O esporte, afinal, funcionara como índice de modernidade e progresso de civilidade em vários contextos onde a prática se desenvolvera. No Brasil, desde os meados do século XIX, notavase forte associação simbólica entre a prática de esportes, a civilidade e a sofisticação dos costumes. (LUCENA, 2001; MELO, 2001; PEREIRA, 2000). E é exatamente nesse sentido que práticas esportivas se apresentavam para os agentes do progresso entre os índios do Brasil Central, isto é, como "uma escola boa de disciplina e cordialidade", recurso para uma vida "mais suave e deliciosa", enfim, um espaço social que reforçava o supostamente necessário aspecto "civilizado" daqueles sertões.

Entre os indígenas, no entanto, não seria necessariamente este o sentido a ser atribuído às práticas esportivas. Tal como já ocorrera em 
outras situações, como no caso da retórica assimilacionista, em que os índios se apropriaram da noção de que eles fazem parte do Brasil como estratégia política para entabular suas próprias reivindicações (GARFIELD, 2011), uma cadeia de significados relacionados aos esportes também poderia se converter num recurso a ser habilmente manipulado em razão dos interesses e necessidades indígenas. Valendo-se de uma prática apresentada inicialmente como estratégia para propagar a "civilização", com o tempo, vários grupos subverteram-lhe o sentido, atribuindo-lhe, então, outros significados: desde o fortalecimento de identidades étnicas tradicionais, passando pela criação de espaços de encontro e diversão, até a possibilidade de promover a articulação de ações políticas através dos esportes (FIALHO; SILVA, 2010; FASSHEBER, 2010; VIANNA, 2008; NASCIMENTO JÚNIOR; FAUSTINO, 2010; TASSINARI, 2003).

\section{Considerações finais}

Índios costumam figurar nas narrativas históricas do Brasil basicamente de duas maneiras: ou eles simplesmente tornam-se invisíveis, ou então aparecem aniquilados pelo progressivo processo modernizador que se impõe sobre eles. Ao menos desde a segunda metade do século XIX, algumas comunidades indígenas brasileiras começaram a ser tratadas exatamente nesses termos: como entidades extintas ou em vias de extinção (ARRUTI, 1995).

A partir de princípios do século XX, o crescente interesse de acadêmicos no estudo de populações indígenas foi paulatinamente reforçando, e de certo modo ampliando esta forma de olhar. Tal postura inauguraria uma longa tradição intelectual, que se estenderia, inclusive, a outras culturas tradicionais que não apenas as indígenas. Dessa maneira, movidos por interesses em larga medida folclóricos, intelectuais foram imprimindo um dado sentido a manifestações culturais populares e tradicionais, supondo-as avançando a passos largos em direção ao desaparecimento, o que animava, inclusive, esforços para registrá-las antes que fosse tarde demais (VILHENA, 1997). Preocupados em identificar sinais de identidade capazes de assegurar a conservação e/ou a autenticidade de culturas em tudo tidas como puras e imaculadas, buscavam-se, no passado, seus traços "essenciais", ao mesmo tempo em que se criticavam quaisquer transformações sofridas por elas. 
Este modo particular de olhar para as dinâmicas sócio-históricas de culturas tradicionais manifestou-se também entre estudiosos do esporte. Em 1989, Jurgen Dieckert e Jokob Mehringer (1989, p. 57), desenvolvendo estudo da cultura lúdica dos índios Canela, no Nordeste brasileiro, manifestaram "preocupação de quanto tempo ainda o admirável povo indígena poderá resistir à pressão da civilização branca e seu sistema de valores e normas, como também sua cultura do lúdico e do movimento poderá ser conservada". Dieckert e Mehringer, como muitos outros antes e depois deles, inseriram-se numa tradição interpretativa preocupada em "conservar" a cultura indígena, tal como imaginavam ser seu estado "original". Tal condição, por sua vez, aparece implicitamente como resultado de um estado de isolamento, em que o contato com a "civilização branca", supostamente forte e poderosa, seria responsável pela desagregação de hábitos e costumes daquela cultura tradicional, supostamente fraca e vulnerável.

Todavia, identidades culturais não são a resultante de um estado de isolamento, se não o produto ativo e intensivo de intercâmbios de ideias, técnicas, práticas e produtos (BARTH, 2000; LINTON, 2000), o que pode dizer respeito também aos esportes. Mais que isso, diferente do que sugerem alguns estudos brasileiros recentes sobre o assunto (RUBIO; FUTADA; SILVA, 2006; ALMEIDA; ALMEIDA; GRANDO, 2010), a incorporação de novas formas de diversão por essas culturas tradicionais não necessariamente implica uma conversão cultural plena e absoluta. Parafraseando Maybury-Lewis (2002), povos indígenas não perdem suas culturas ao abandonarem o arco e a flecha, bem como os ocidentais não perderam a sua ao abandonarem o cavalo e a charrete. Nesse sentido, a interação de diferentes grupos através de jogos e outros lazeres pode significar apenas mais um veículo de interação entre diferentes culturas, e não o canal para o aniquilamento de costumes e estilos de vida.

Muitas vezes, ao incorporarem novas práticas ou objetos, grupos indígenas atribuem-lhes sentidos e significados particulares, de acordo com seus próprios sistemas culturais (SAHLINS, 1997a; 1997b). Em várias situações tem sido este o caso da assimilação de práticas esportivas (DIAS, 2011). O fato de os esportes serem o produto histórico da modernidade, não significa que eles sejam, por princípio, incompatíveis com culturas tradicionais, pois, a priori, não existe oposição irreconciliável entre tradição e modernidade, nem tampouco a modernidade é um produto do Ocidente (HUNTINGTON, 1997; EI- 
SENSTADT, 2000; GOODY, 2008). Índios podem perfeitamente incorporar a eletricidade, telefones celulares ou a prática de esportes e continuarem vivendo suas vidas como índios. A cultura indígena não é algo estático, alheio às transformações e aprisionada no passado. Nesse sentido, é no mínimo politicamente pernicioso tentar advogar que povos tradicionais devam viver como se imagina terem vivido seus antepassados do século XVI, sob o risco de não mais serem tradicionais.

Como se tornou lugar-comum entre estudiosos do assunto, o esporte é uma prática social. Mais do que um frase de efeito e vazia de sentido, esta assertiva quer dizer que o conteúdo dessas práticas se define a partir de um conjunto de relações sociais, e não a partir de características ontológicas. O esporte, portanto, não tem "essência", e seus sentidos históricos são definidos por circunstâncias cotidianas do seu uso social (APPADURAI, 1995; HORNE, 1998). Assim, fiéis, de fato, ao velho entendimento antropológico que afirma serem dinâmicas todas as culturas, podemos dizer que atualmente os esportes também constituem parte das mais "autênticas" tradições indígenas - se é que ainda faz algum sentido falar em "autenticidade" de tradições nos dias de hoje. A própria vivacidade da revitalização étnica atualmente em curso entre muitas dessas culturas tradicionais de certo modo confirma o diagnóstico (BARTH; STREIFF-FENAART; POUTIGNAT, 1998; LIFSCHITZ, 2006; GIDDENS, 1997; NOVAES, 1999). Pois contrariando todas as previsões, várias comunidades indígenas, bem como outros grupos tradicionais, protagonizam em várias partes um intenso processo de revitalização étnica, no qual práticas globalizadas, tais como os esportes, funcionam, muitas vezes, como ferramentas através das quais essas populações podem se mobilizar e articular suas próprias pautas de reivindicações?

The church, the State and the ball: sport history among indians from Brazil central

\section{Abstract}

The purpose this work is to analyze the history of the diffusion of sports among Indians from Brazil Central, showing some preliminary data about it, addition to summarize a research's agenda and a possible theory for interpretation this relati-

7-Para exemplos na América do Norte e na África, ver Allison (1979); Cheska (1988); Darby (2000); Mills (2012); Parasch (1997). 
onship. Both state's actions and religious was the main responsible by the diffusion of sports among Indians this region. Against other interpretations, the historical meaning this process didn't meaning the destruction of traditional indigenous culture, although this had was intention of many of those responsible for this process.

Keywords: History. Sport. Indians.

La iglesia, el Estado y la pelota: la historia del deporte entre los indios del Brasil central

\section{Resumo}

El objetivo de este trabajo es analizar la historia de la difusión de deportes entre los indios del Brasil Central, presentando algunos datos preliminares sobre esto, también resumiendo una agenda de investigación y un posible marco teórico para la interpretación de esta relación. Las acciones de Estado y de los misioneros religiosos fueran los dos pasos principales para la difusión del deporte entre los indios de esta región. Diferente de las interpretaciones actuales sobre esto, el significado histórico de este proceso no represento necesariamente la destrucción de las culturas indígenas, aunque estos eran, por lo general, la intención de los agentes responsables por esto proceso.

Palavras chave: Historia. Desportes. Indios.

\section{Referências}

ALLISON, M. T. On the ethnicity of ethnic minorities in sport. Quest, vol. 31, n. 1, 1979, p. 50-56.

ALMEIDA, A. J. M. de; ALMEIDA, D. M. F. de; GRANDO, B. S. As práticas corporais e a educação do corpo indígena: a contribuição do esporte nos Jogos dos Povos Indígenas. Revista brasileira de ciências do esporte, Florianópolis, vol. 32, n. 2-4, 2010, p. 59-74

APPADURAI, A. Playing with modernity: the decolonization of Indian cricket. In: BRECKENRIDGE, C. A. (ed.). Consuming modernity: public culture in a South Asian world. Minneapolis: University of Minnesota Press, 1995, p. 23-47

A PLATÉA. Os índios Carajás praticam o futebol, São Paulo, 24 de novembro de 1930.

ARRUTI, J. M. A. Morte e vida do Nordeste indígena: a emergência étnica como fenômeno histórico regional. Estudos Históricos, Rio de Janeiro, vol. 8, n. 15, 1995, p. 57-94. 
AYALA, C. (org.). Album graphico do estado de Matto Grosso. Coumbá / Hamburgo: [s/ed], 1914.

BALE, J.; CRONIM, M. Introduction: sport and postcolonialism. In: BALE, J.; CRONIM, M. (eds.). Sport and posticolonialism. New York: Berg, 2003, p. 1-13.

BARTH, F. O guru, o iniciador e outras variações antropológicas. Rio de Janeiro: Contra Capa Livraria, 2000.

BARTH, F.; STREIFF-FENART, J.; POUTIGNAT, P. Teorias da etnicidade. São Paulo: Ed. da Unesp, 1998.

BIGIO, E. dos S. Linhas telegráficas e integração dos povos indígenas: as estratégias políticas de Rondon. Brasília: CGDOC / FUNAI, 2003.

BINFIELD, C. George Williams and the YCMA: a study in Victorian Social Attitudes. London: Heinemann, 1973.

BORGES, Carlos N. F. "Um só coração e uma só alma": as influências da ética romântica na intervenção educativa salesiana e o papel das atividades corporais. Tese (Doutorado). Universidade Gama Filho, Rio de Janeiro, 2005.

BORGES, D. R. S. Rio Araguaia: corpo e alma. São Paulo: Ibrasa, 1986.

CANCELLA, K. B. A fundação da primeira sede da associação cristão de moços na América Latina e sua atuação como fomentadora da prática esportiva no Rio de Janeiro pós-republicano. Recorde, Rio de Janeiro, vol. 3, n. 2, dez. 2010.

. O esporte e as Forças Armadas na Primeira República: das atividades gymnasticas às participações em eventos esportivos internacionais (1890-1922). Rio de Janeiro: PPGHC / UFRJ, Mimeo, 2011.

CASTILHO, M. A. de. Os índios bororos e os salesianos na missão dos Tachos. Campo Grande: Universidade Católica Dom Bosco, 2000. 
CHESKA, A. T. Ethnicity, identity, and sport: the persistence of power. International Review for the Sociology of Sport, vol. 23, n. 2, 1988, p. 85-95.

COMISSÃO RONDON. Linhas telegráficas estratégicas de Mato Grosso ao Amazonas: photographias de construcção, expedições e explorações desde 1900 a 1922. Rio de Janeiro: Ministério da Guerra, 1922.

COSTA, A. F. da. Relatório ao Serviço de Protecção aos Índios no Estado de Goyaz, relativo ao anno de 1929. vol. 1 e 2. Goyaz: Ministério da Agricultura, Indústria e Comércio, 1930.

DARBY, P. Football, colonial doctrine and indigenous resistance: mapping the political persona of Fifa's African constituency. Culture, Sport, Society, vol. 3, n. 1, 2000, p. 61-87.

DELGADO, A. A.; GÓMEZ, G. A. Yanomami football in the high Ocamo (Amazons State, Venezuela): the Mabetiteri case. Journal of Human Sport and Exercise, vol. 5, issue 3, 2010, p. 228-328.

DIACON, T. A. Rondon. São Paulo: Companhia das Letras, 2006.

DIAS, C. Esporte e lazer em culturas tradicionais. In: SILVA, A M.; FALCÃO, J. L. C.; TUCUNDUVA, T. (orgs.). Práticas corporais em comunidades quilombolas de Goiás. Goiânia: Editora da PUCGoiás, 2011. p. 93-116.

DIECKERT, J.; MEHRINGER, J. Cultura do lúdico e do movimento dos índios Canela. Revista brasileira de ciências do esporte, vol. 11, n. 1,1989 , p. $54-57$.

EISENSTADT, S. Multiple modernities. Daedaelus, vol. 129, issue 1, 2000, p. 1-29.

FASSHEBER, J. R. M. Etno-deporto indígena: a antropologia social e o campo entre os Kaingang. Brasília: Ministério do Esporte, 2010.

FIALHO, V.; SILVA, G. Política, alteridade e negociação nos I Jogos Indígenas de Pernambuco. Tellus, Campo Grande, ano 10, n. 18, 2010, p. 65-81. 
FILHO, U. de F. O indígena e a mensagem do Segundo Advento: missionários adventistas e povos indígenas na segunda metade do século XX. Tese (Doutorado), Universidade de São Paulo, 2006.

FRANCISCO, A. J. Educação e modernidade: os salesianos em Mato Grosso, 1894-1919. Cuiabá: Ed. da UFMG, 2010.

GAGLIARDI, J. M. O indígena e a República. São Paulo: Hucitec / Edusp, 1989.

GARFIELD, S. A luta indígena no coração do Brasil. São Paulo: Ed. Unesp, 2011.

GIDDENS, A.; BECK, U.; LASH, S. Modernização reflexiva: política, tradição e estética na ordem social moderna. São Paulo: Ed. da Unesp, 1997.

GODOI, A. Do meu tempo. Goiânia: Imprensa da UFG, 1969.

GONÇALVES, C. B. O movimento ecumênico protestante no Brasil e a implantação da Missão Cauiá em Dourados. Dissertação (Mestrado), Universidade Federal de Grande Dourados, Dourados, 2009.

GOODY, J. O roubo da história: como os europeus se apropriaram das idéias e invenções do Oriente. São Paulo: Contexto, 2008.

HORNE, J. The politics of Sport and Leisure In Japan. International Review for the Sociological of Sport, vol. 33, n. 2, 1998, p. 171-182.

HUNTINGTON, S. O choque de civilizações e a recomposição da ordem mundial. Rio de Janeiro: Objetiva, 1997.

LASMAR, D. P. O acervo imagético da Comissão Rondon no Museu do Índio, 1890-1938. Rio de Janeiro: Museu do Índio, 2008.

LIFSCHITZ, J. A. Neocomunidades: reconstruções de territórios e saberes. Estudos históricos, Rio de Janeiro, n. 38, jul./dez. 2006, p. 6785. 
LIMA, A. C. de S. O governo dos índios sob a gestão do SPI. In: CUNHA, M. C. da (org.). História dos índios no Brasil. São Paulo: Companhia das letras, 1992, p. 155-172.

LINTON, R. O homem: Uma introdução à antropologia. São Paulo: Martins Fontes, 2000.

LUCENA, R. de F. O esporte na cidade: Aspectos do esforço civilizador brasileiro. Campinas: Autores Associados, 2001.

MACIEL, L. A. Cultura e tecnologia: a constituição do serviço telegráfico no Brasil. Revista brasileira de história, São Paulo, v. 21, n. 41, 2001, p. 127-144.

MANGAN, J. A. Athleticism in the Victorian and Edwardian public school: the emergence and consolidation of an educational ideology. Cambridge: Cambridge University Press, 1981.

MAYBURY-LEWIS, D. A sociedade xavante. Rio de Janeiro: Francisco Alves, 1984.

. A antropologia numa era de confusão. Revista brasileira de ciências sociais, vol. 17, n. 50, 2002, p. 15-23.

MELO, V. A. de. Cidadesportiva: primórdios do esporte no Rio de Janeiro. Rio de Janeiro: Relume-Dumará / Faperj, 2001.

MELLO, D. S. B. de. Entre índios e revoluções: pelos sertões de São Paulo, Mato Grosso e Goiás de 1911 a 1941. São Paulo: Soma, 1980.

. Relatório apresentado ao Snr. Tenente-Coronel Alencarliense Fernandes da Costa. Goyaz: Ministério da Agricultura, Indústria e Comércio, 1931.

MENEZES, C. Missionários e guerreiros: o apostolado salesiano entre os Xavante. In: WRIGHT, Robin M (org.). Transformando os deuses: os múltiplos sentidos da conversão entre os povos indígenas no Brasil. Campinas: Ed. da Unicamp, 1999, p. 309-342.

MONTEIRO, O. S. do N. Remiscências: Goiás d'antanho, 19071911. Goiânia: Oriente, 1974. 
NASCIMENTO, E. F. V.-B. C. do. Educar, curar, salvar: uma Ilha de civilização no Brasil tropical. Maceió: Editora da Universidade Federal de Alagoas, 2007.

NASCIMENTO JÚNIOR, J. R. do; FAUSTINO, R. C. Jogos indígenas: o futebol como esporte tradicional Kaingang. Pensar a prática, Goiânia, vol. 12, n. 3, 2010.

NOVAES, A. A outra margem do Ocidente. In: NOVAES, A. (org.). A outra margem do Ocidente. São Paulo: Companhia das letras, 1999, p. 7-14.

O DEMOCRATA. Inspectoria de indios, Goyaz, 07 de novembro de 1924, n. 381, p. 1.

PARASCH, V. Variations in Race Relations: Sporting Events for Native Peoples in Canada. Sociology of Sport Journal, vol. 14, n. 1, 1997, p. 1-21.

PEREIRA, L. A. de M. Footballmania: uma história social do futebol no Rio de Janeiro, 1902-1938. Rio de Janeiro: Nova Fronteira, 2000.

PUTNEY, C. Muscular Christianity: manhood and sports in Protestant America. Harvard: Harvard Univeristy Press, 2001.

ROCHA, L. M. A política indigenista no Brasil: 1930-1967. Goiânia: Ed. da UFG, 2003.

RONDON, C. M. da S. Relatório dos trabalhos realizados entre 1900 e 1906 pela Comissão de Linhas Telegráficas do estado de Mato-Grosso, apresentado às autoridades do Ministério da Guerra. Rio de Janeiro: Departamento de Imprensa Nacional / Conselho Nacional de Proteção aos Índios, 1949 (publicação n. 69-70).

RUBIO, K.; FUDATA, F. de M.; SILVA, E. C. da. Os jogos indígenas e as contradições do confraternizar e competir. Revista brasileira de ciências do esporte, Campinas, v. 28, n. 1, 2006, p. 105-119.

NETO, J. M. dos S. Visão do jogo: primórdios do futebol no Brasil. São Paulo: Cosac \& Naify, 2002.

SAHLINS, M. O "pessimismo sentimental" e a experiência etnográfi- 
ca: por que a cultura não é um "objeto" em via de extinção (parte I). Mana, Rio de Janeiro, vol. 3, n. 1, 1997a., p. 41-73.

. O "pessimismo sentimental" e a experiência etnográfica: por que a cultura não é um "objeto" em via de extinção (parte II). Mana, Rio de Janeiro, vol. 3, n. 2, 1997b., p. 103-150.

SILVA, H. R. da. Nos sertões do Araguaia: narrativas da expedição às glebas bárbaras do Brasil Central. São Paulo: Saraiva, 1959.

TACCA, F. de. A imagética da Comissão Rondon. Campinas: Papirus, 2001.

TASSINARI, A. M. I. No bom da festa: o processo de construção cultural das famílias Karipuna do Amapá. São Paulo: Ed. da Unesp, 2003.

TEIXEIRA DA SILVA, F. C. Futebol: uma paixão coletiva. In: TEIXEIRA DA SILVA, F. C.; SANTOS, R. P. dos (orgs.). Memória social dos esportes - futebol e política: a construção de uma identidade nacional. Rio de Janeiro: Mauad / Faperj, 2006, p. 15-32.

VIANNA, F. L. B. Boleiros do cerrado: índios xavantes e o futebol. São Paulo: Annablume / Fapesp / ISA, 2008.

VILHENA, L. R. Projeto e missão: o movimento folclórico brasileiro, 1947-1964. Rio de Janeiro: Funarte/Fundação Getulio Vargas, 1997.

WATSON, N. J.; WEIR, S.; FRIEND, S. The Development of Muscular Christianity in Victorian Britain and Beyond. Journal of Religion and Society, vol. 7, 2005, p. 1-21.

WRIGHT, R. História indígena no noroeste da Amazônia: hipóteses, questões e perspectivas. In: CUNHA, M. C. da (org.). História dos índios no Brasil. São Paulo: Companhia das letras, 1992, p. 253-266.

Recebido em: 23/11/2011

Revisado em: 20/01/2012

Aprovado em: 03/02/2012

Pensar a Prática, Goiânia, v. 15, n. 1, p. 1-271, jan./mar. 2012 


\section{Endereço para correspondência}

cag.dias@bol.com.br

Cleber Dias

Universidade Federal de Goiás

Faculdade de Educação Física

Rodovia Goiânia - Nerópolis, Km-12

Campus Samambaia

Caixa Postal: 131

CEP: $74001-970$

Goiânia - GO 